\title{
Assessing Water Quality by Establishing a National Water Quality Information System Case Study: Ismailia Canal
}

\author{
A. Habash. ${ }^{1}$, Ahmed H. Mahmoud ${ }^{2}$ \\ ${ }^{1}$ National Water Research Center, Cairo, Egypt \\ ${ }^{2}$ Civil Engineering Department, Faculty of Engineering, Al-Azhar University, Cairo, Egypt
}

Correspondence Author: Ahmed H. Mahmoud. Civil Engineering Department, Faculty of Engineering, Al-Azhar University, Cairo, Egypt e-mail: ahmedbadr3000@ hotmail.com

Received date: 28 January 2019, Accepted date: 13 March 2018, Online date: 28 March 2019

Copyright: () 2019 A. Habash, Ahmed H. Mahmoud. This is an open-access article distributed under the terms of the Creative Commons Attribution License, which permits unrestricted use, distribution, and reproduction in any medium, provided the original author and source are credited.

\begin{abstract}
In terms of the importance of management action and regular assessment of water quality, this research was initiated with the objective of establishing a NWQIS "National Water Quality Information System" to assist decision makers to assess water quality, where Ismailia Canal was taken as a case study. Primarily, literature in the field of water quality was reviewed. Water samples were extracted and water quality data in Ismailia Canal Catchment were assembled for the period 2008-2016 and analyzed. A NWQIS was tooled to access the assembled data and transform them to accessible information that could be visualized, from which thematic maps were produced. Finally, conclusions were deduced. In addition, recommendations for future researches and Engineering practice were suggested.
\end{abstract}

Keywords: Statistical analysis, irrigation, water quality, information systems

\section{INTRODUCTION}

Egypt is facing a double folded problem. The first, it is challenged by exponential population increase. The second, this increase is accompanied by environmental degradation. However, there is an ever-increasing economic growth in Egypt. Accordingly, management and regular assessment of water quality to meet these challenges are essential. Accordingly, this research was commenced with the impartial of establishing a NWQIS "National Water Quality Information System" to assist decision makers to assess water quality, where Ismailia Canal was selected to be a case study.

Ismailia canal is $128 \mathrm{~km}$ long with a depth that varies between 1 and $3 \mathrm{~m}$. Its width ranges between 30 and $70 \mathrm{~m}$. The canal discharge ranges between 135 and $440 \mathrm{~m} 3$ /s, and it serves 349440 ha.

The research investigation phases are presented, as follows:

- Literature review in the field of water quality

- Water sampling and data assembly

- NWQIS and visualizing information

- Producing thematic maps

- Conclusions and recommendations

\section{LITERATURE REVIEW}

Literature in the field of water quality was reviewed, from which it was clear that many researchers investigated the water quality. Among them, for example are, as follows:

Sanders (1998) stated that the water quality is a limiting factor for being used in different purposes.

- Lu, Zhi Chen and Wenquan Liu (2014) developed a GIS- eutrophication assessment module and a graphical user interface (GUI). It integrates fuzzy risk calculation and heavy metal risk evaluation. It presents the results as color-coded maps indicating risk levels. 
- M. Shaban et al. (2010) carried a research that relied on a tool to design a framework for cost-effective pollution control measures, where GIS support decision support systems "DSS" for water quality management.

- Shaban (2017) assembled data collected for the period 2000-2013 for El-Salam Canal and achieved a percentile analysis to facilitate better handling of data.

- Ahmed Habash et al. (2018) Tailor-made protocol for assessing water quality of irrigation canals: Case study of El Nubaria canals, Egypt.

- Mohsen and El Gammal (2015) achieved a statistical analysis adapted to water quality monitoring.

- Abdel Gawad et al. (2005) investigated water quality in Bahr-Baqar Drain in the Eastern Delta of Egypt. They used principal components analysis "PCA" and hierarchical cluster analysis "HCA".

- Camacho et al. (2015) investigated water quality in India, where they implemented HCA and PCA.

- Viswanath et al. (2015) assessed the groundwater quality of Kozhikode City, Kerala, India, using multiple linear regressions.

\section{WATER SAMPLING AND DATA ASSEMBLY}

Data were assembled from Ismailia Canal; figures (1) and (2), during the period 2008-2016, at different locations; table (1). Also, the samples were analyzed according to the Standard Methods for the Examination of Water and Wastewater, where the sampling frequency was 12 at all monitoring locations in Ismailia Canal. In addition, the selected sites for water sampling were at point source pollution and mixing locations in order to assess pollution loads along the canal.

The water quantity was measured by Acoustic Doppler Current Profilers "ADCPs", where ADCP is a sonar device that measures water velocities in layers according to the defined acoustic frequency to define 34 water quality parameters, such as:

microbiological parameters, oxygen-related parameters, nutrients cations, extended cations, metals, trace elements, salinity, macro-ions, temperature and $\mathrm{PH}$.

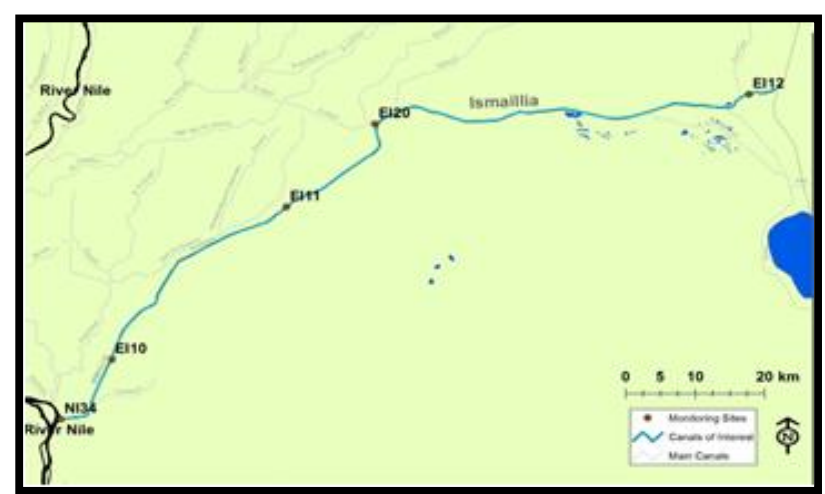

Figure (1) Layout map of Delta Canals with selected monitoring sites

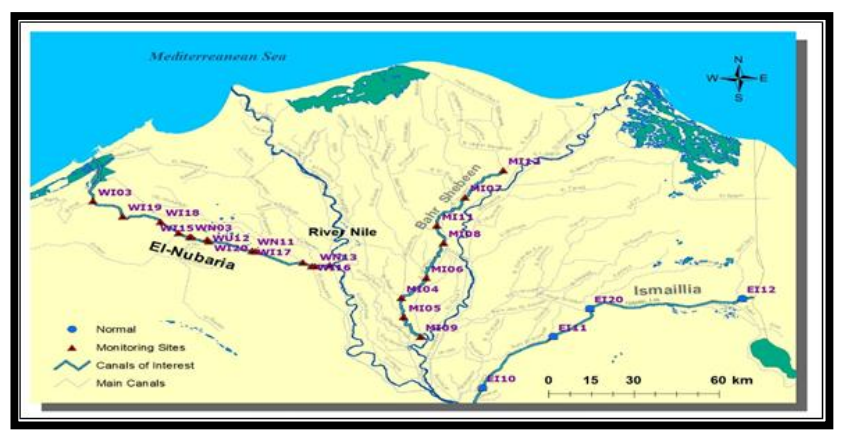

Figure (2) Layout map of Ismailia Canal with selected monitoring sites

Table (1): Sampling sites of Ismailia canal

\begin{tabular}{|l|c|c|l|l|}
\hline \multicolumn{1}{|c|}{ Code } & $\mathrm{E}$ & $\mathrm{N}$ & \multicolumn{1}{c|}{ Canal Name } & \multicolumn{1}{c|}{ Catchment } \\
\hline NI34 & 31.24292 & 30.10579 & Ismailia & Intake \\
\hline EI10 & 31.3177 & 30.19357 & Ismailia & From the source to about 20 Km \\
\hline EI11 & 31.57557 & 30.41808 & Ismailia & From the source to about 50 Km \\
\hline EI12 & 32.26735 & 30.58745 & Ismailia & Before the station of drinking water at Ismailia city \\
\hline EI20 & 31.70678 & 30.54008 & Ismailia & Ismailia canal after 70 km from the source \\
\hline
\end{tabular}




\section{NWQIS AND VISUALIZING INFORMATION}

Water samples were analyzed, and an NWQIS for assessing water quality was tooled. The basic idea of the NWQIS is to merge some of the previous statistical analysis tools to produce results relative to the specific monitoring objectives. This ensures data consistency; in case they were assembled from different origins and were analyzed by different entities.

NWQIS was developed with the Python language. It was tooled to facilitate data representation and analysis. NWQIS is an open source that provides fast efficient numerical so as statistical analysis. It is widely used. It could provide spatial data representation of water quality status; could perform quick statistical analysis for water quality data and could present the main results in an easily saved form. Its script executes multiple tasks without intermediate data manipulation. Its main script workflow is presented the in figure (3). It includes descriptive statistics, percentile analysis and pollutant load representation by Box and Whisker Plots.

NWQIS provides a map to the water quality status for the clustered parameters; figure (4). This would assist policy-makers and government personnel.

It is worthy of mentioning that NWQIS was designed according to the Egyptian WQ standards for irrigation canals. It was tooled via 5 phases, as follows:

- Phase (1): Descriptive statistics and comparison with standards: During this phase, descriptive statistics and comparison to national quality standards (Law 48 for 1982 and its amendment 2013) were carried out to provide statistical data (i.e. Max., Min., Mean, Median, Range and Standard Deviation).

- Phase (2): Pollution Loads: All through this phase, the relative importance of each tributary as a point source to the Ismailia Canal in terms of water pollution loads was identified to the period 2008 - 2016 through boxplots to the reuse pumping stations (i.e. Dilengat Extension, El-Bustan, El-Umoum 3 and Drain 3.

- Phase (3): Percentile Analysis (PA): Throughout this phase, PA is achieved to assess pollution levels at the monitored locations against national quality standards (Law 48 for 1982 and its amendment 2013), where they are represented by box plots.

- Phase (5): WQ Mapping : During this phase, NWQIS works with the selected parameters to perform analysis and create shape files; figure (5), where a simple function uses the predefined water quality allowable limits to define the status classification at each monitoring station (i.e. Normal, Accepted, Moderate and Severe); table (2). Also, NWQIS performs graphical representation and mapping of proposed selected results from its interface; figure (6).

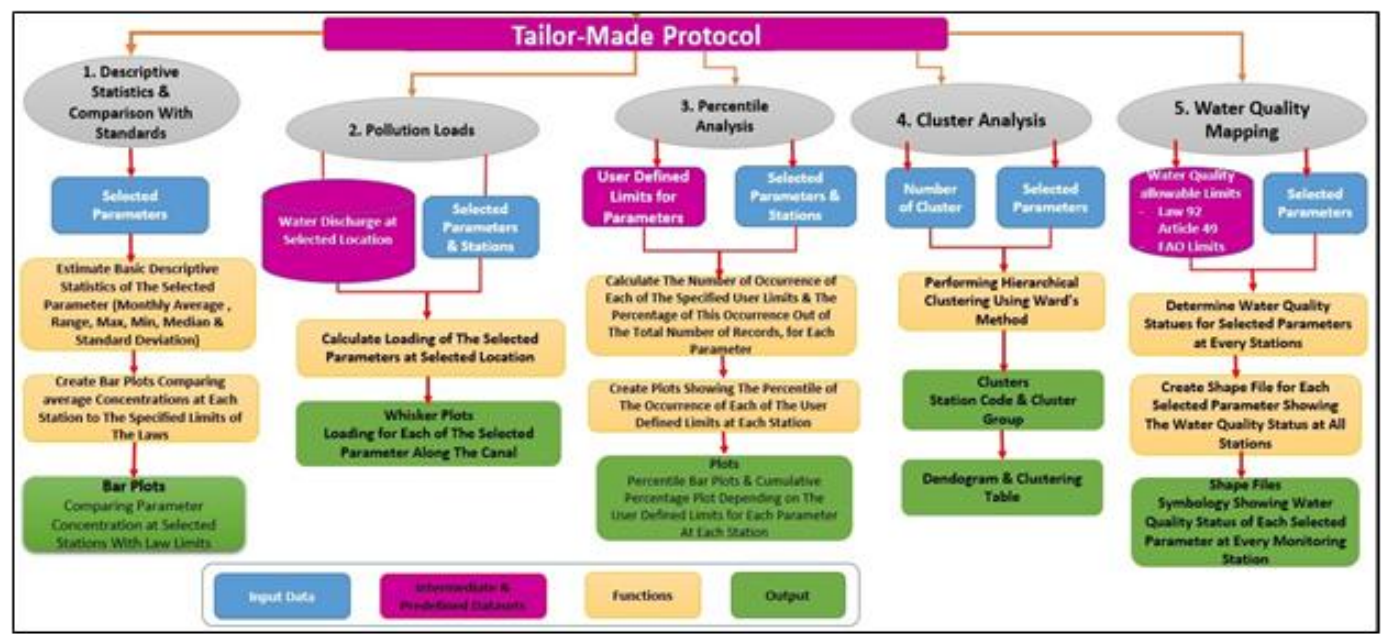

Figure (3) Workflow an NWQIS script tool

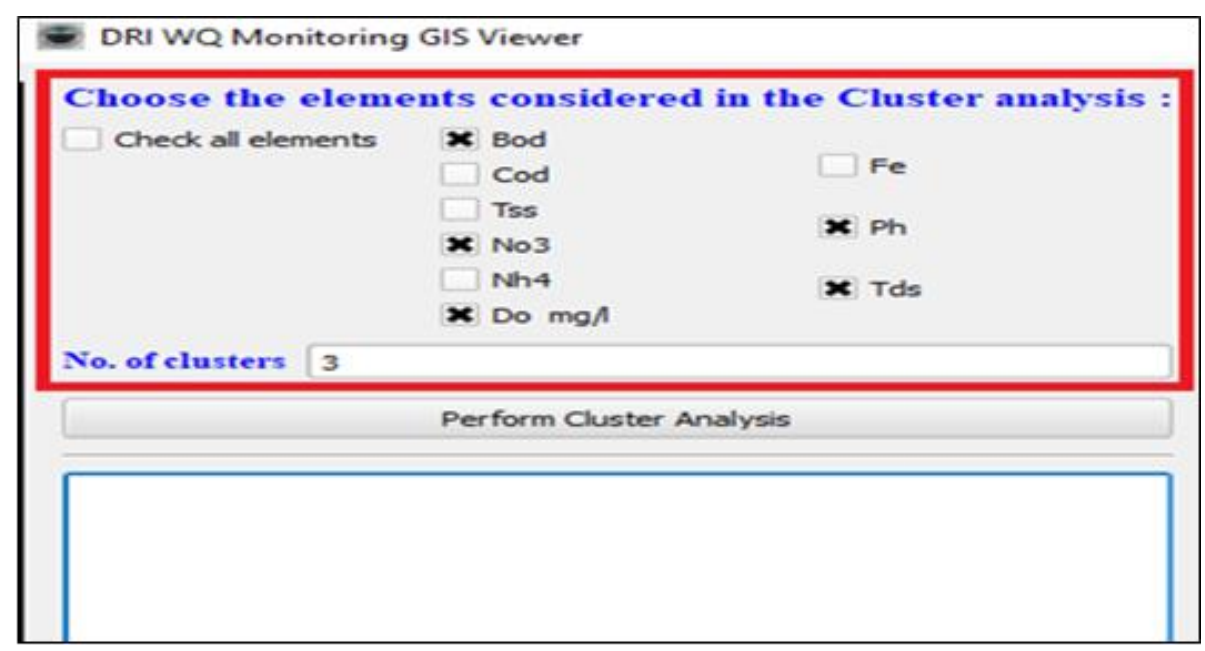


Figure (4) NWQIS, selection of parameters to be clustered

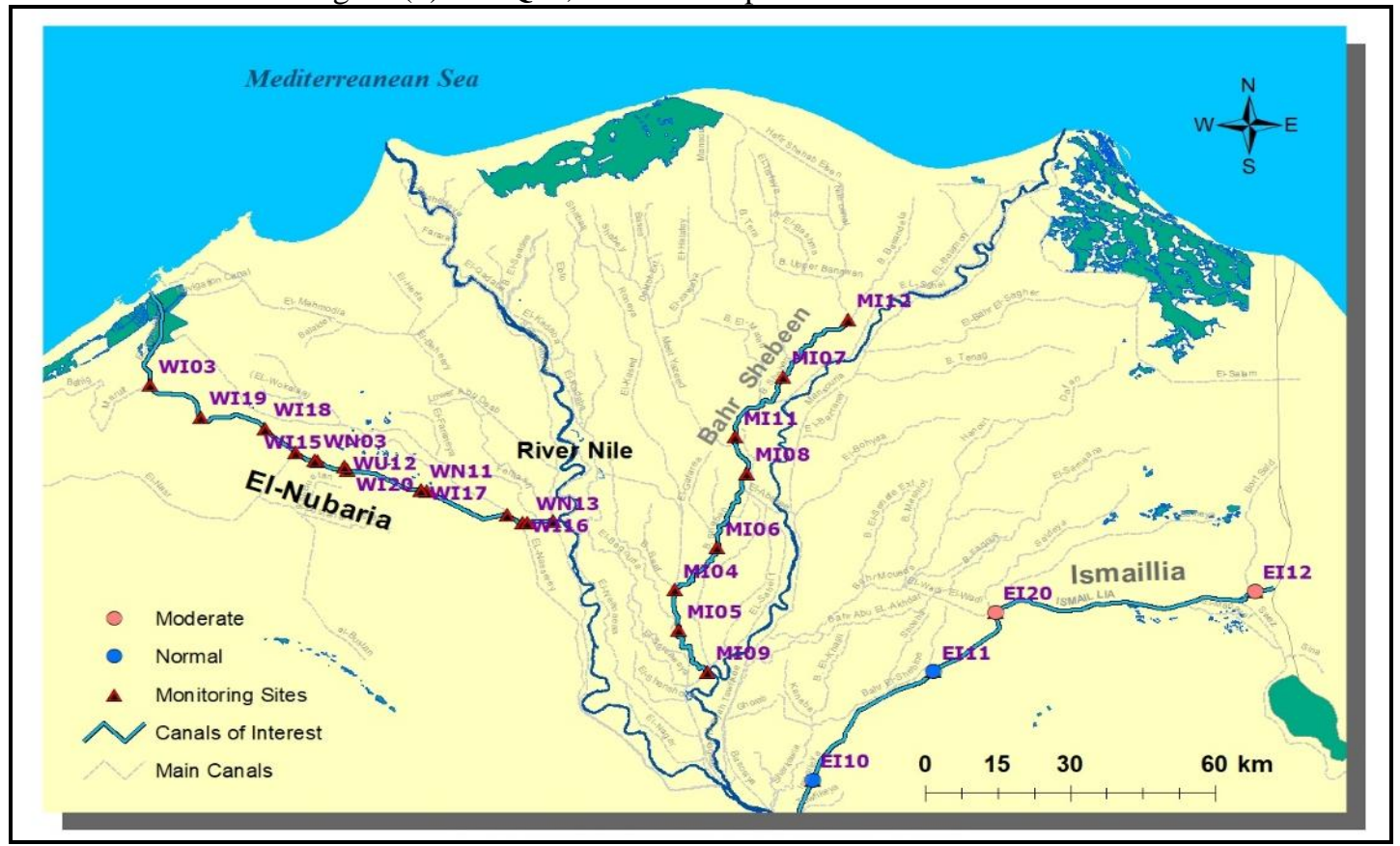

Figure (5) Created shape files to map water quality parameters at the selected sites

Table (2): Classification Terms

\begin{tabular}{|c|c|c|c|c|}
\hline Classification & Normal & Accepted & Moderate & Severe \\
\hline BOD $(\mathrm{mg} / \mathrm{l})$ & $0-5$ & 6 & $7-10$ & $>10$ \\
\hline $\mathrm{COD}(\mathrm{mg} / \mathrm{l})$ & $0-9$ & 10 & $11-20$ & $>20$ \\
\hline $\mathrm{PH}$ & 7.5 & $6.5-8.5$ & 6 & $<6$ \\
\hline $\mathrm{TDS}(\mathrm{mg} / \mathrm{l})$ & $0-400$ & 500 & $600-1000$ & $>1000$ \\
\hline
\end{tabular}

\section{DRI WQ Monitoring GIS Viewer}

\section{Choose the elements for shapefiles creation :}

Check all elements

\begin{tabular}{|c|c|c|c|c|c|c|}
\hline Bod & ए & Tn & $\square \mathrm{Mg}$ & $\square$ & Sar & \\
\hline Cod & E & $\mathrm{Fe}$ & $\square \mathrm{Na}$ & $x$ & Do $\mathrm{mg} /$ & $\square \mathrm{Ni}$ \\
\hline Tss & $x$ & $\mathrm{~Pb}$ & $\square K$ & $\square$ & $\mathrm{Cd}$ & \\
\hline No3 & $x$ & $\mathrm{Ph}$ & $\square \mathrm{HCO} 3$ & $\square$ & Cu & bor on \\
\hline Nh4 & $x$ & Tds & Q So4 & Б & Mn & Temprature \\
\hline$T p$ & ए & $\mathrm{Ca}$ & $\square \mathrm{Cl}$ & $\square$ & $\mathrm{Zn}$ & \\
\hline
\end{tabular}

Return to Main Window

Choose the rule/Art. to consider in analysis :

X Egyptian Law 1992 Art. 49 limits

FAO Limits

Create Shapefiles!

Figure (6) NWQIS interface for selections and shape files creation

\section{RESULTS AND DISCUSSIONS}

The output of NQWIS was obtained and analyzed, for the 5 phases, as follows:

- Phase (1): Descriptive statistics and comparison with standards: The results of this phase determined the water quality along Ismailia Canal; table (3). From the table, it was clear that the water quality was within limits of Articles no. 51 and no. Forty-nine of Egyptian law 48 for the year 1992 and its amendment for the year 2013. Also, the table provided an annual descriptive statistics to the monitoring sites (i.e. WI01, WI03, WI16, WN03 and WN13), where the mean value of 
the BOD was $18 \mathrm{mg} / \mathrm{l}$, at WI01, COD was $26 \mathrm{mg} / \mathrm{l}$, pH was 8.3 and TDS was $1557 \mathrm{mg} / \mathrm{l}$. Similar results were obtained for the other monitoring locations. On the other hand, it was noticed that the salinity increases at WN03 so as WN13, which indicated that the long-term reuse for irrigation is not possible without adequate drainage. Also, high levels of BOD5 and COD were observed in drainage water. However, their concentration exceeded the limits; figures (7) to (10).

- Phase (3): Percentile Analysis: The results of this phase signpost that the Percentile analysis for (WI14), (WI16) and (WI01) complied with national quality standards (Law 48 for 1982 and its amendment 2013) in terms of BOD, COD, DO and TDS; figures (12) to (15).

- Phase (5): WQ Mapping: The results in this phase indicated the BOD status that were mostly high, while the COD, DO and TDS were within limits along Ismailia Canal; figures (16) to (19).
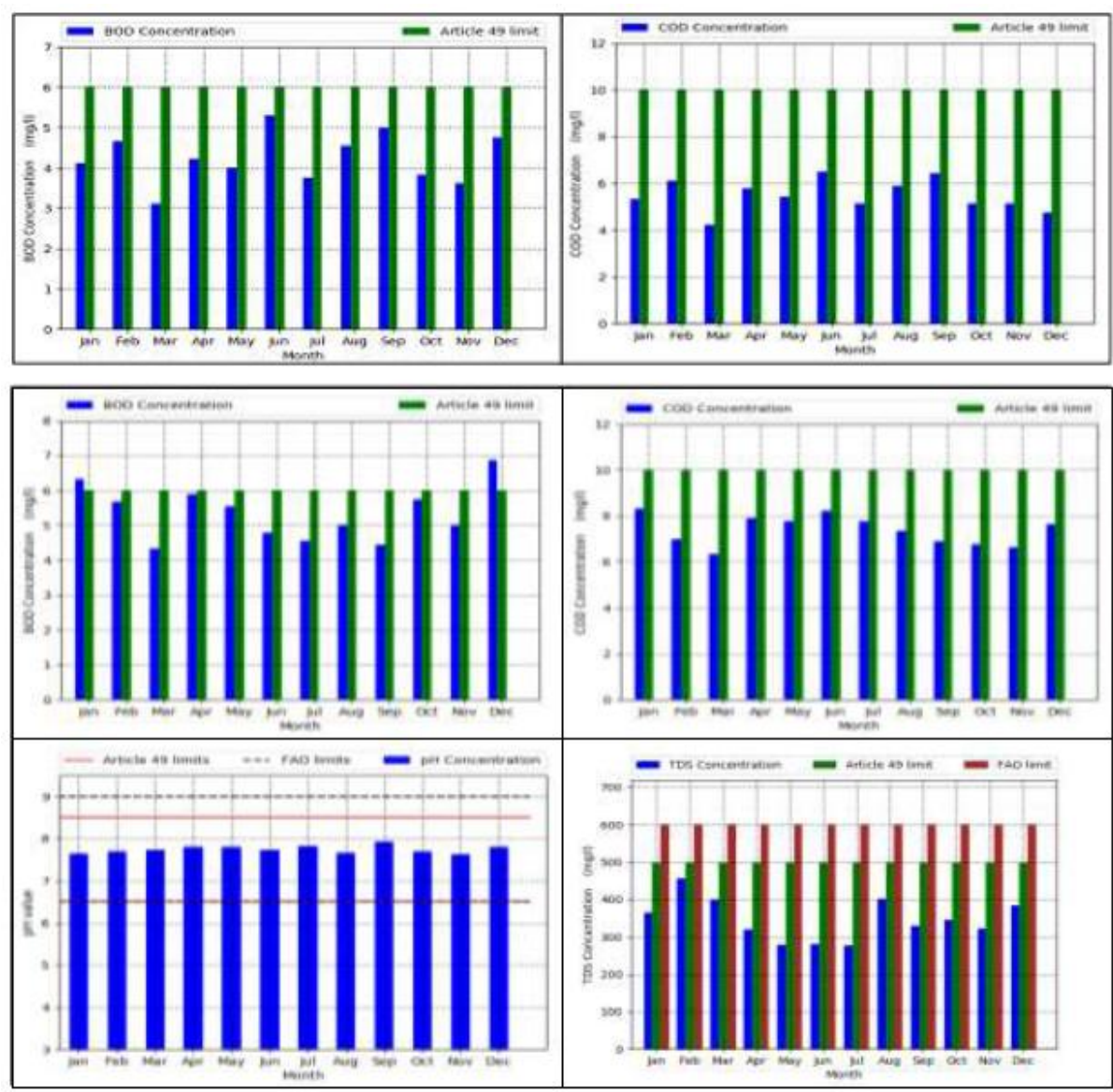

Figure (7) Comparison to standards at EI10

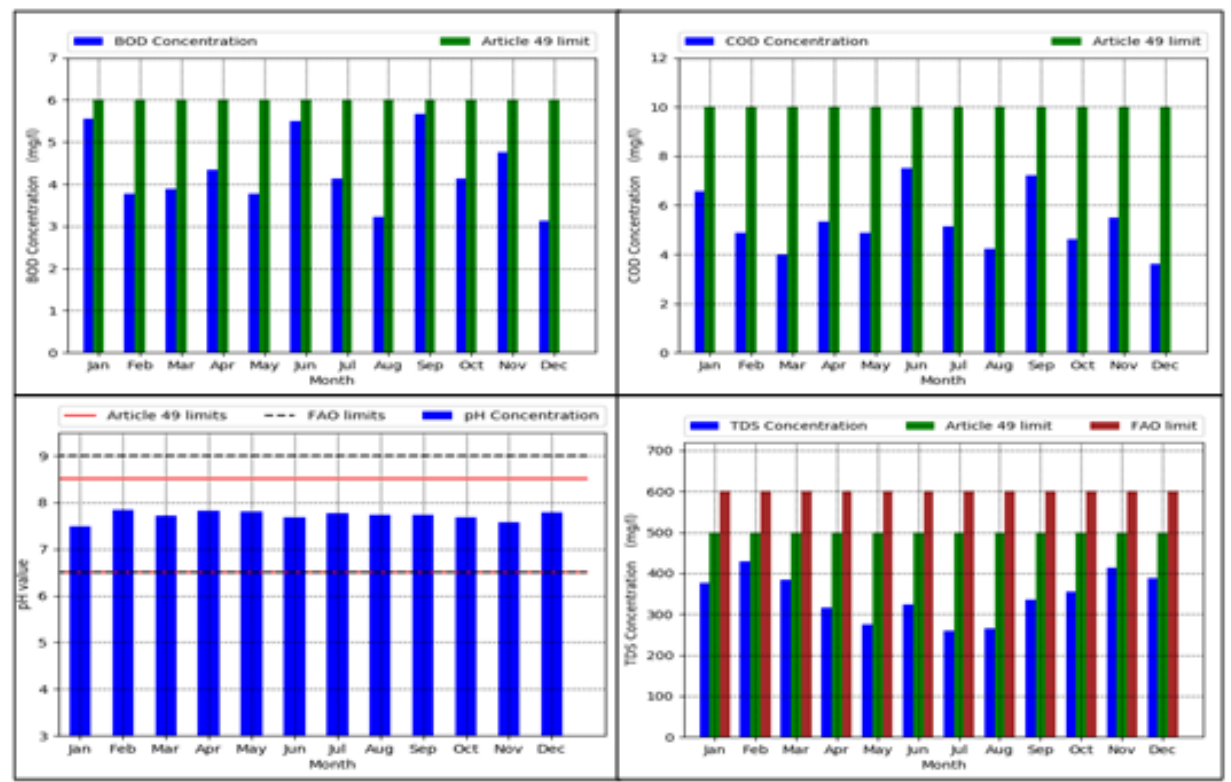

Figure (8) Comparison to standards at EI11 


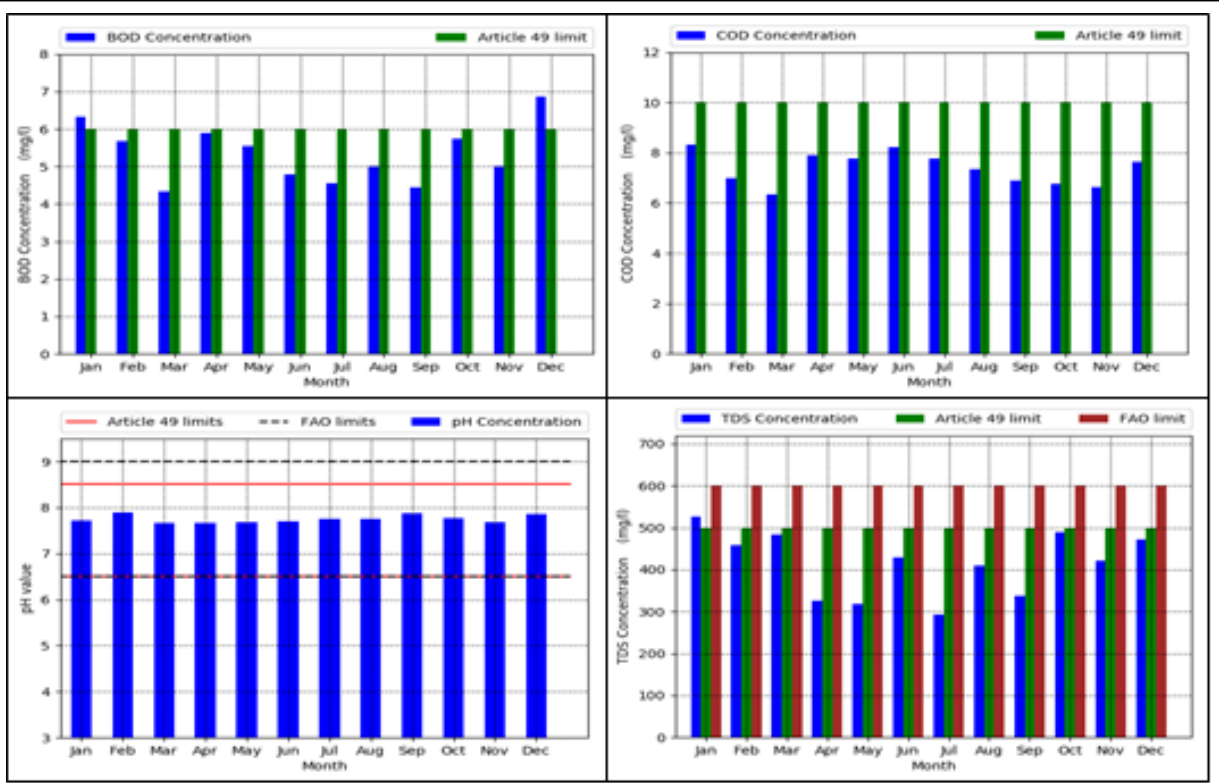

Figure (9) Comparison to standards at EI12

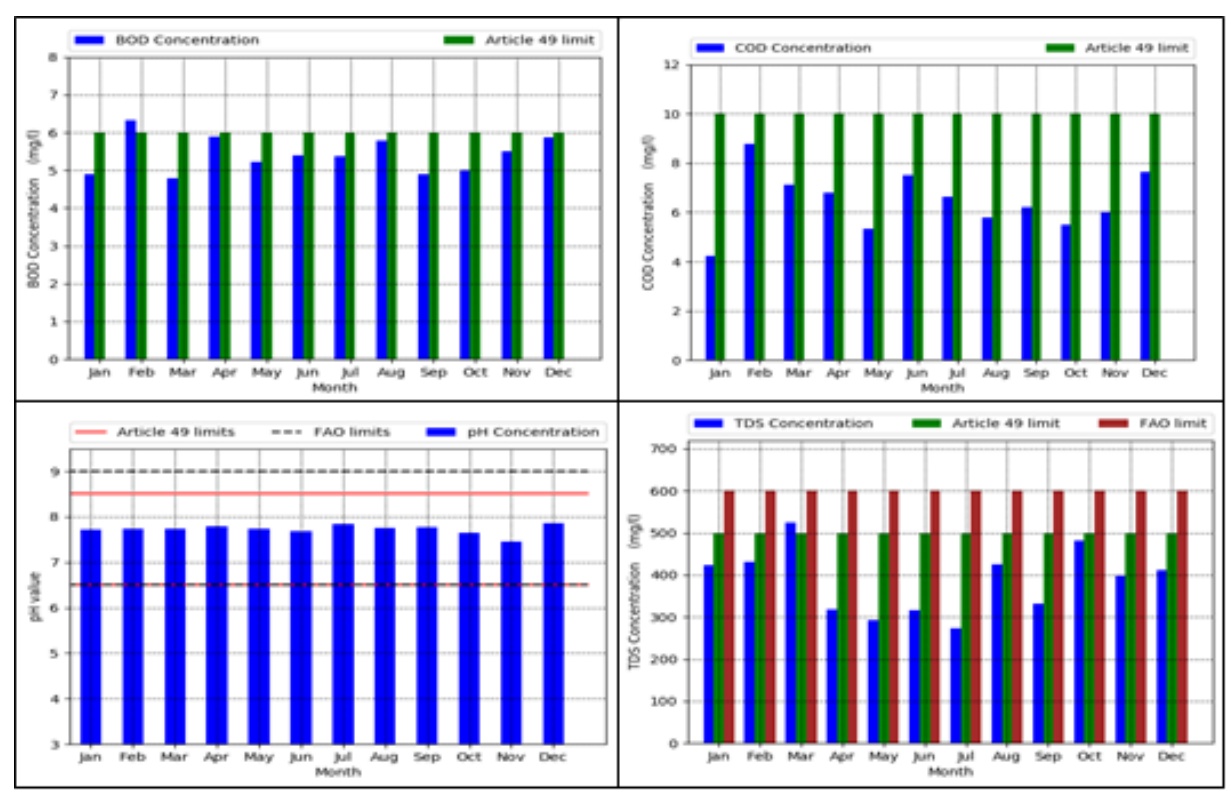

Figure (10) Comparison to standards at EI20

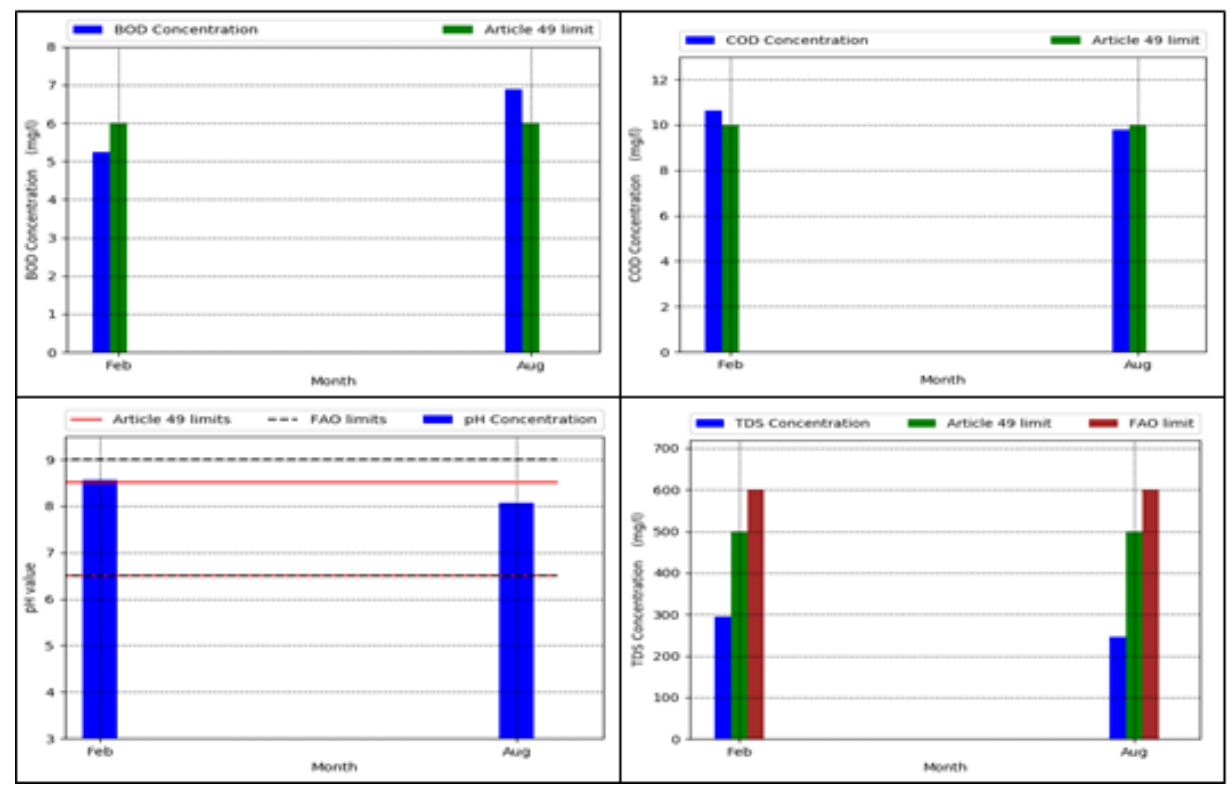

Figure (11) Comparison with standards for monthly measured WQPs. NL34 location 


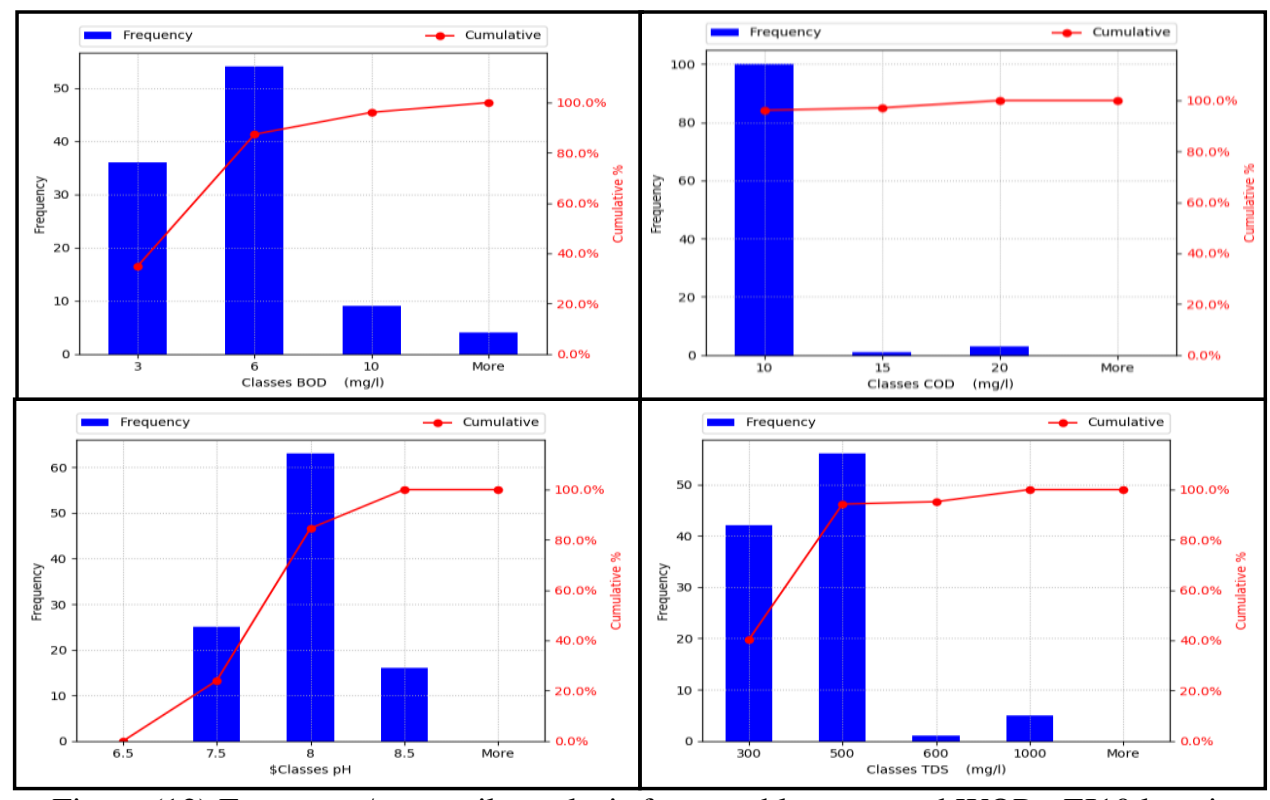

Figure (12) Frequency/percentile analysis for monthly measured WQPs. EI10 location

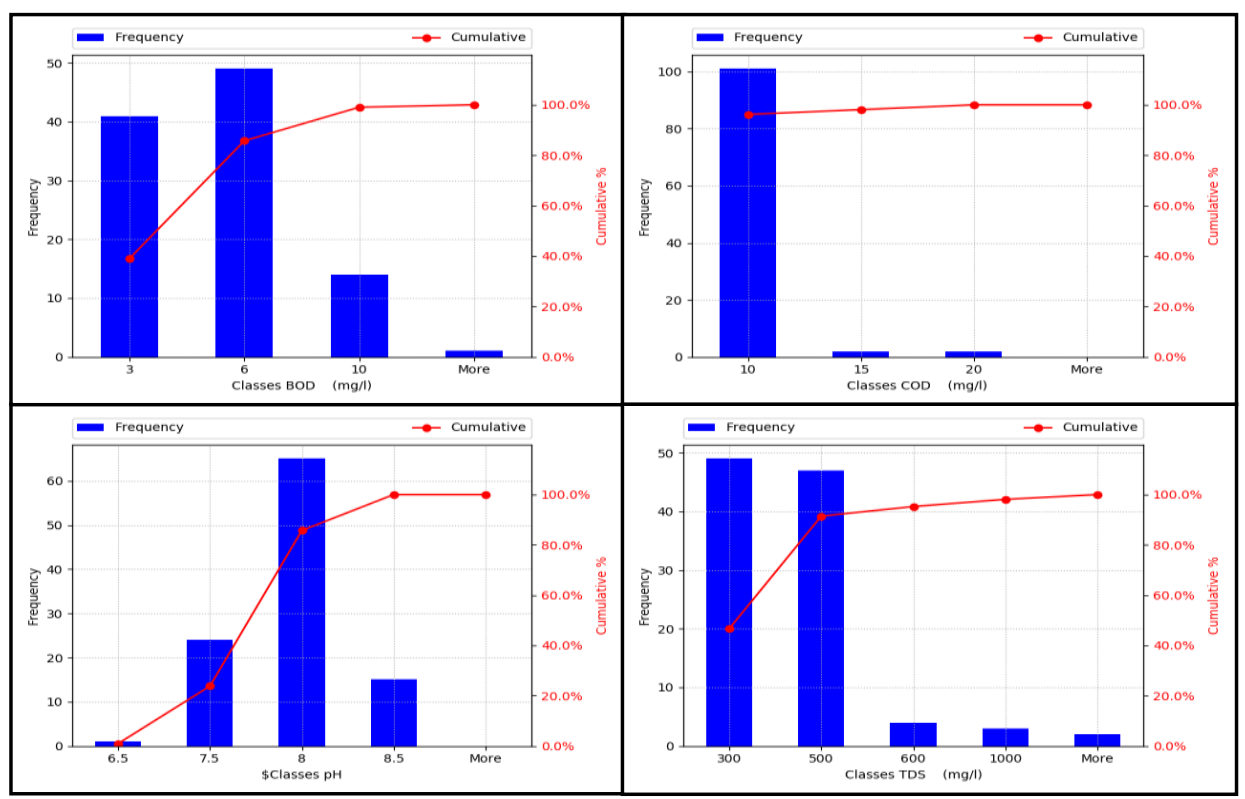

Figure (13) Frequency/percentile analysis for monthly measured WQPs. EI11 location

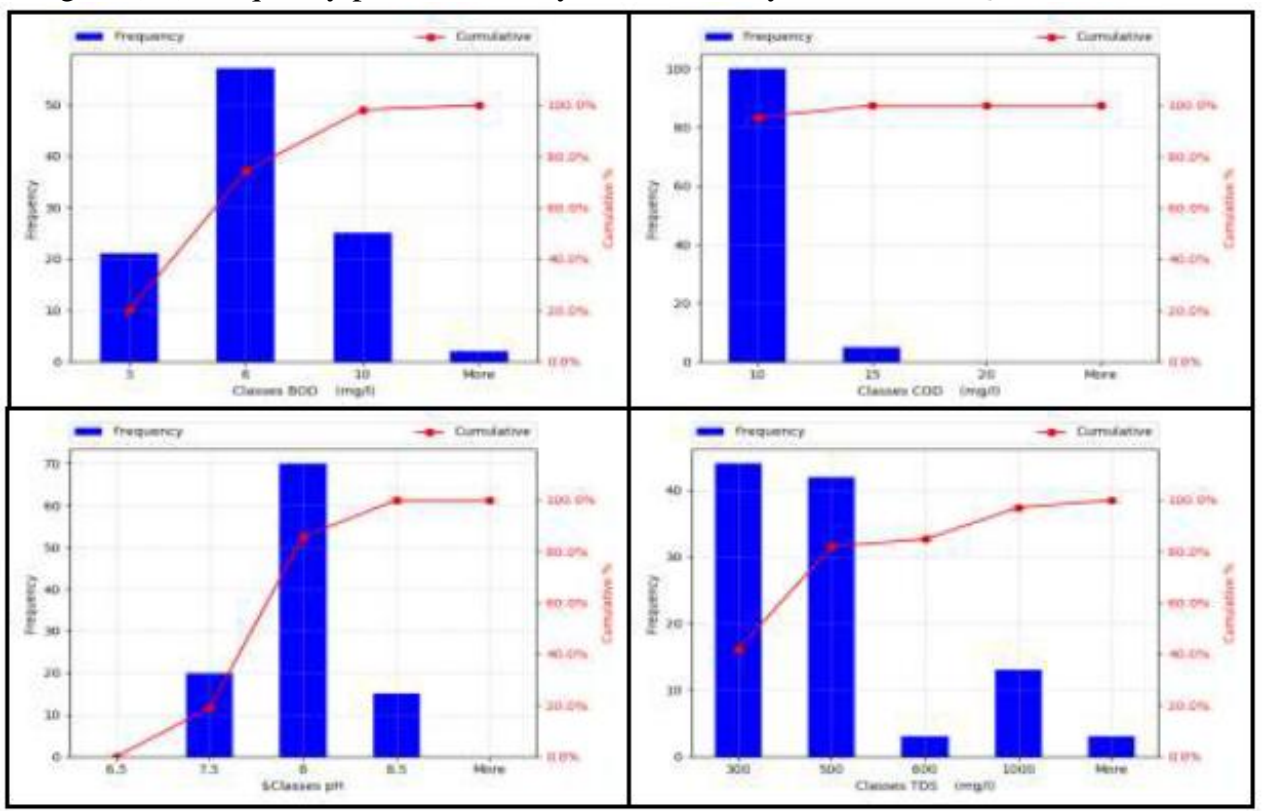


Figure (14) Frequency/percentile analysis for monthly measured WQPs: EI12 location

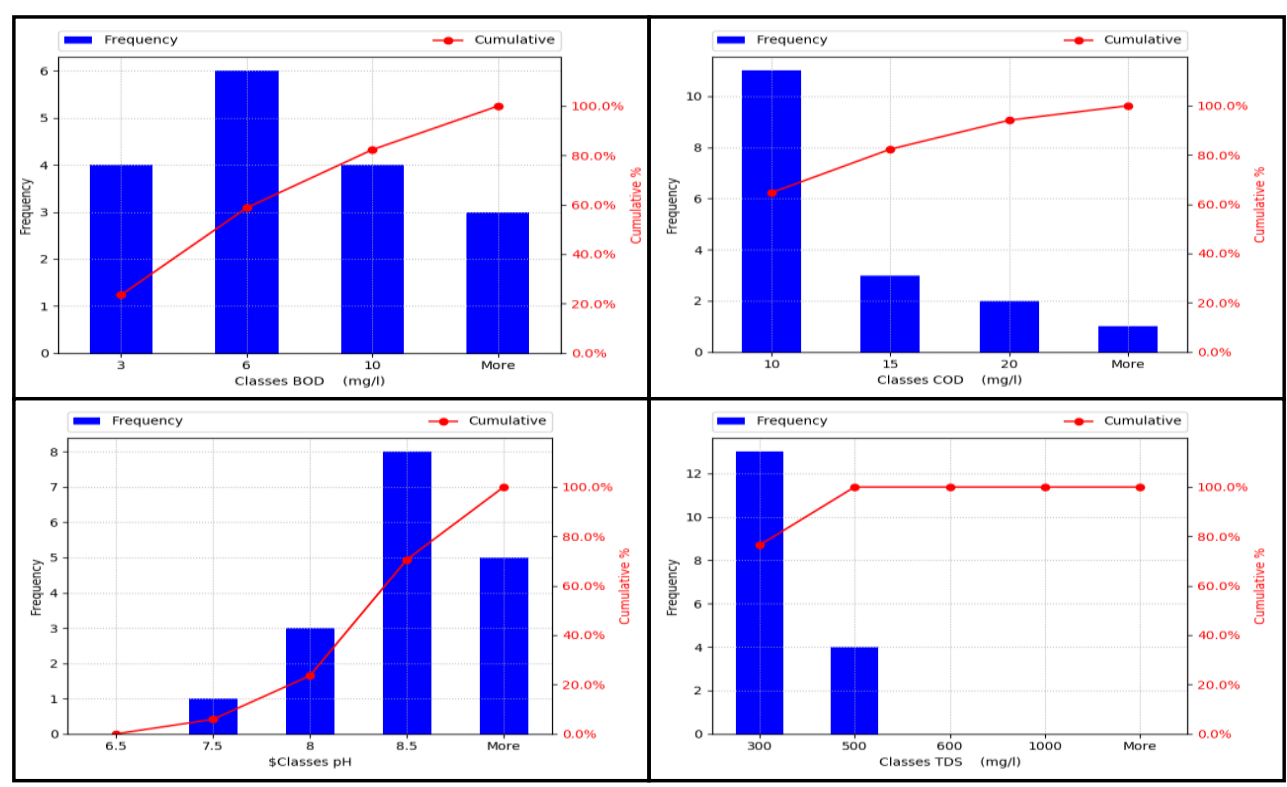

Figure (15) Frequency/percentile analysis for monthly measured WQPs: NL34 location

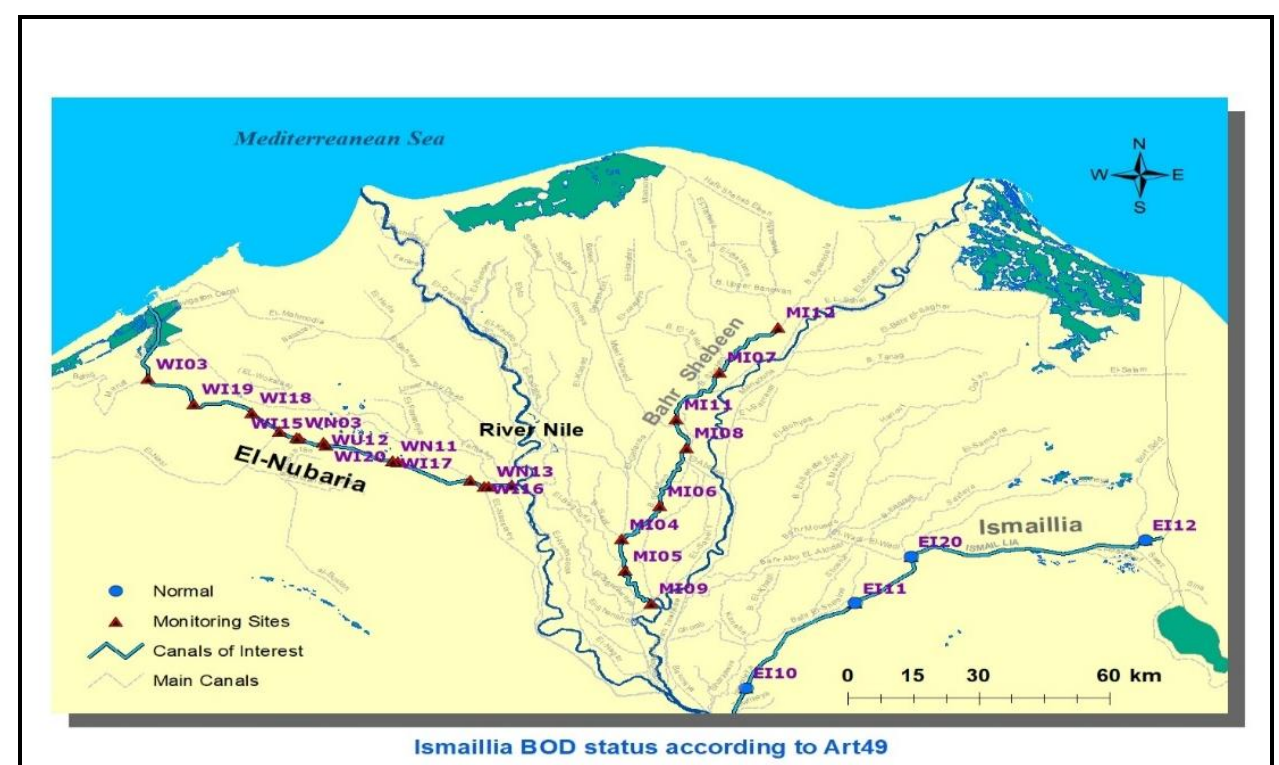

Figure (16) BOD status along Ismailiairrigation canal 


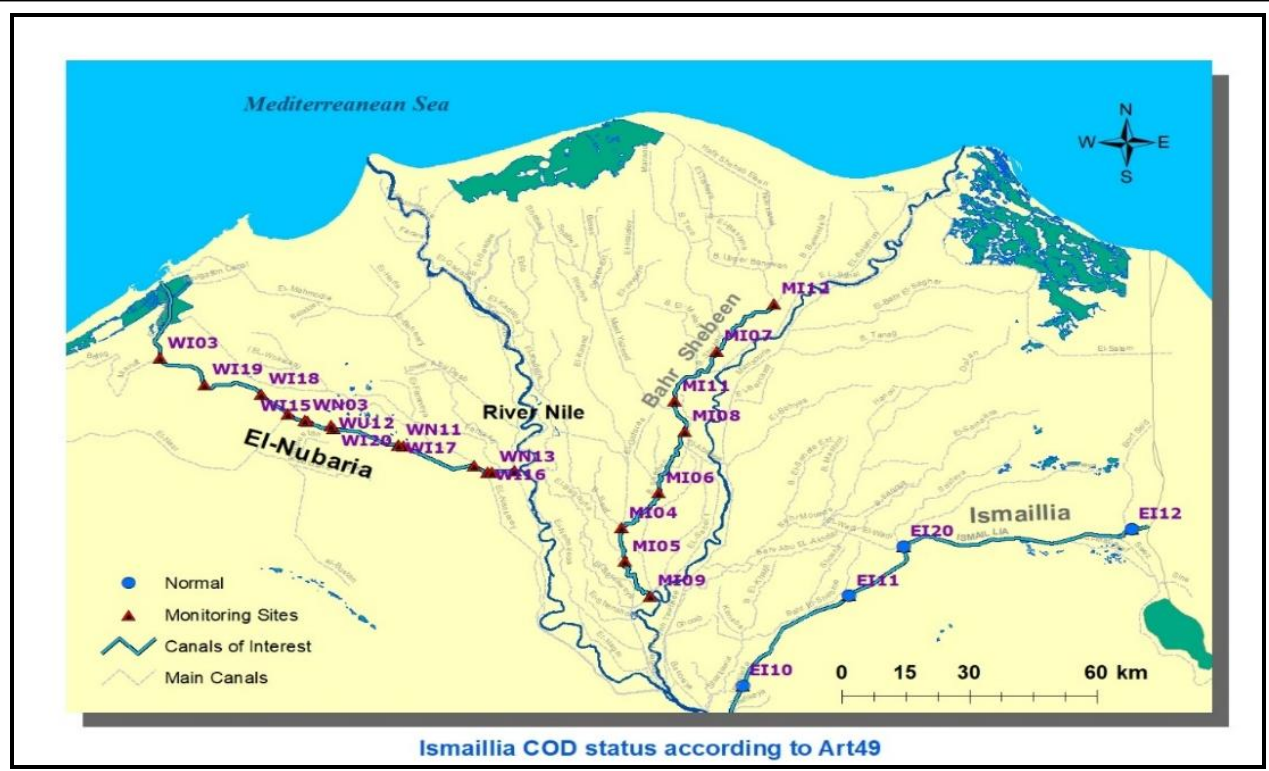

Figure (17) COD status along Ismailiairrigation canal

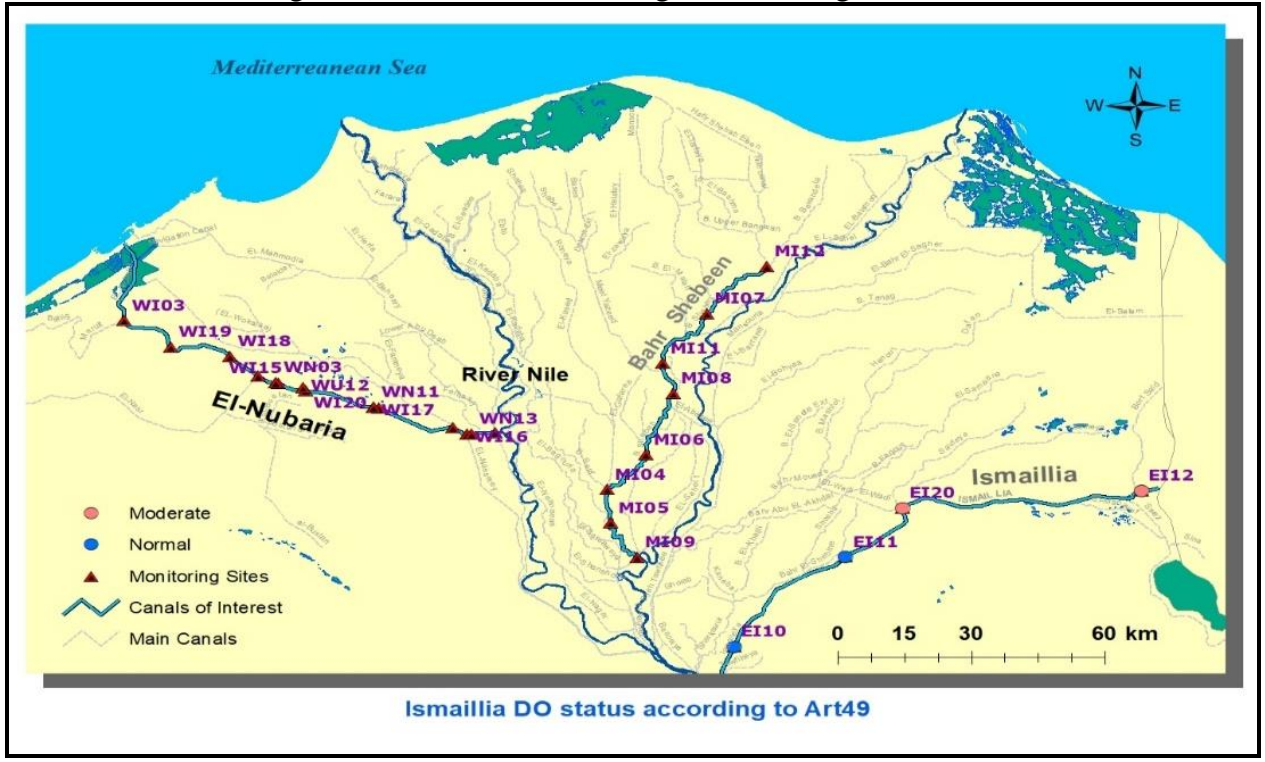

Figure (18) DO status along Ismailiairrigation canal

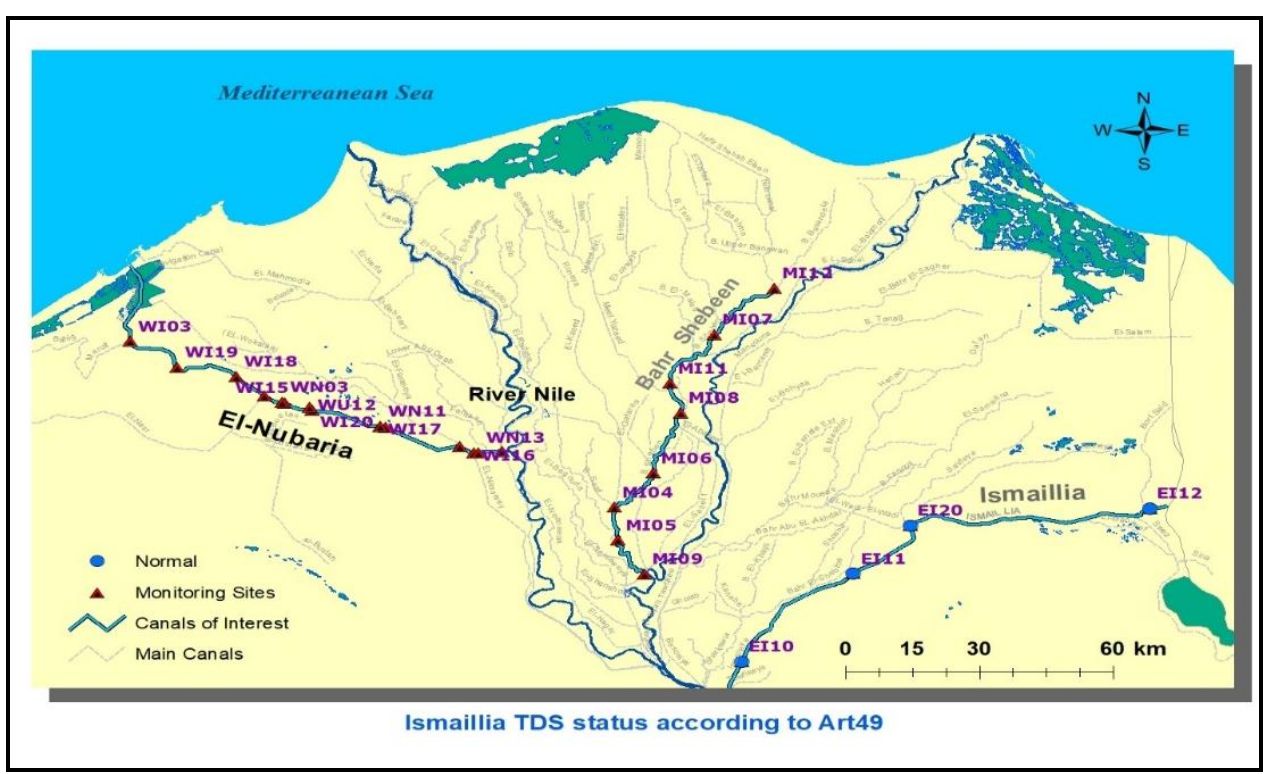

Figure (19) TDS status along Ismailiairrigation canal 


\section{CONCLUSIONS AND RECOMMENDATIONS}

Based on the above, some conclusions were deduced, as follows:

- The water quality status in the Ismailia Canal is of high salinity with biological drainage effluents loads. However, it is within the general moderate water quality status of the Egyptians standards.

- Python is simple easy to read format that could identify and keep track the of data type.

- NWQIS proofed its integration to assess water quality of Ismailia Canal within the Egyptian Environmental Laws.

- NWQIS simplifies dataflow effort and reduces the human error, as it provides a dynamic visualization of the modelling results.

- The produced maps will assist decision makers in controlling pollution and managing the canal basin.

- The proposed NWQIS indicated its effectiveness and applicability to check compliance with water quality standards.

- The proposed NWQIS could allocate waste loads from different sources and could classify water quality status.

Some recommendations were suggested for future research, as follows:

- Extend and generalize NWQIS tool for other irrigation and drainage basins in Nile Delta.

- Investigate python format, as it can handle multiple threads to synchronize inputs and outputs. In addition, it runs multiple operations.

Some recommendations were suggested for Engineering practice, as follows:

- Implement NWQIS tool for other monitoring locations within the irrigation network in Egypt.

- Implement NWQIS, as it is a high-speed low-cost tool that could automate programming functionalities.

\section{REFERENCES}

Abdel-Gawad ST, Khalil BM, Awadallah AG. (2005), Statistical assessment of a water quality monitoring system using principal components and cluster analyses, Journal of Engineering and Applied Science, Faculty of Engineering, Cairo University 52(6) 1083-101.

Ahmed Habash et al.(2018), Tailor-made protocol for assessing water quality of irrigation canals: Case study of El Nubaria canal, Egypt", Water Science, 2018, Volume 32, Issue 2 Pages 179-400.

Arifuzzaman K, Rahman M, Hassan N. (2015), Irrigation channel water quality monitoring by multivariate statistical methods in the interior coastal district of Bangladesh, IOSR Journal of Environmental Science, Toxicology and Food Technology (IOSR-JESTFT) 9(4) Ver. II:: 74-80 .e-ISSN: 2319-2402, p- ISSN: 2319-2399

Awadallah AG, Yousry M. (2012), Identifying homogeneous water quality regions in the Nile river using multivariate statistical analysis, Water Resources Management Journal 26(7): 2039-2055.

Camacho JB, Delgado ER, Quintal IB, Zarate del Valle PF, Chuken UJL, Guareñol EO , Bobadilla Jia, Salazar SG. (2015), Water quality assessment of a tropical Mexican lake using multivariate statistical techniques, Journal of Environmental Protection, 6: 215-224.

Mediterranean Environmental Technical Assistance Program (METAP) (2001), Country Report on Water Quality Management and Potential METAP Interventions-Egypt, available at: www.metap.org

ohsen YM, El Gammal HAA (2015), Factor analysis as a tool to identify water quality index parameters along the Nile river, Egypt, Journal of American Science 11(2): 36-44.

Phung D, Huang C, Rutherford S, Dwirahmadi F, Chu C, Wang X, Nguyen M, Nguyen NH, Do CM, Nguyen TH, Dinh TA.(2015), Temporal and spatial assessment of river surface water quality using multivariate statistical techniques: a study in Can Tho City, a Mekong Delta area - Vietnam, Environmental Monitoring and Assessment 187(5): 4474.

Sanders (1998), Water quality monitoring networks in water and waste water systems analysis, Elsevier Science Publishers B.V. The Netherlands, pp 204-216.

Shaban M. (2017), Statistical framework to assess water quality for irrigation and drainage canals, Irrig. and Drain. 66: 103117 (2017).

Singovszka E, Balintova M. (2012), Application factor analysis for the evaluation surface water and sediment quality., Chemical Engineering Transactions 26: 183-8.

Viswanath NC, Kumarb PGD, Ammad KK. (2015), Statistical analysis of quality of water in various watersheds for Kozhikode City, Kerala - India, Aquatic Procedia 4: 1078-85. 